\title{
The Silesian Registry of Out-of-Hospital Cardiac Arrest: Study design and results of a three-month pilot study
}

\author{
Klaudiusz Nadolny ${ }^{1,2,3}$, Kamil Bujak ${ }^{4}$, Michał Kucap ${ }^{1,5}$, Przemysław Trzeciak ${ }^{4}$, \\ Bartosz Hudzik ${ }^{4,6}$, Artur Borowicz ${ }^{1}$, Mariusz Gąsior ${ }^{4}$ \\ ${ }^{1}$ Voivodeship Rescue Service, Katowice, Poland \\ ${ }^{2}$ Department of Emergency Medicine, Medical University of Bialystok, Poland \\ ${ }^{3}$ Faculty of Medicine, Katowice School of Technology, Katowice, Poland \\ ${ }^{4} 3^{\text {rd }}$ Department of Cardiology, Silesian Center for Heart Diseases, \\ Faculty of Medical Sciences in Zabrze, Medical University of Silesia, Katowice, Poland \\ ${ }^{5}$ Department of Anesthesiology Nursing and Intensive Care, Faculty of Health, \\ Medical University of Gdansk, Poland \\ ${ }^{6}$ Department of Cardiovascular Disease Prevention, Faculty of Health Sciences in Bytom, \\ Medical University of Silesia, Katowice, Poland
}

\begin{abstract}
Background: Despite the introduction of the concept known as "Chain of Survival" has significantly increased survival rates in patients with out-of-hospital cardiac arrest (OHCA), short-term mortality in this group of patients is still very high. Epidemiological data on OHCA in Poland are limited. The aim of this study was to create a prospective registry on OHCA covering a population of 2.7 million inhabitants of Upper Silesia in Poland. Presented herein is the study design and results of a 3-month pilot study.

Methods: The Silesian Registry of Out-of-Hospital Cardiac Arrest (SIL-OHCA) is a prospective, population-based registry of OHCA, of minimum duration which was planned for 12 months; from January $1^{\text {st }}, 2018$ to December $31^{\text {st }}, 2018$. The first 3 months of the study constituted the pilot phase. The inclusion criterion is the occurrence of OHCA in the course of activity of the Voivodeship Rescue Service in Katowice, Poland.

Results: During the 3-month pilot phase of the study there were 390 cases of OHCA in which cardiopulmonary resuscitation was undertaken. Estimated frequency of $\mathrm{OHCA}$ in the population analyzed was 57 per 100,000 population per year. Shockable rhythm was present in 25.8\% of cases. Return of spontaneous circulation was achieved in $35.1 \%$ of the whole cohort. $28.7 \%$ of patients were admitted to the hospital, including $2.8 \%$ of patients, who were admitted during an ongoing cardiopulmonary resuscitation.

Conclusions: Prehospital survival of patients with OHCA in Poland is still unsatisfactory. It is believed that data collected in SIL-OHCA registry will allow identification factors, which require improvement in order to reduce short- and long-term mortality of patients with OHCA. (Cardiol J 2020; 27, 5: 566-574) Key words: out-of-hospital cardiac arrest, cardiopulmonary resuscitation, emergency medical services, registry
\end{abstract}

Address for correspondence: Kamil Bujak, MD, Silesian Centre for Heart Diseases, ul. Marii Skłodowskiej-Curie 9, 41-800 Zabrze, Poland, tel: +48 323733 860, fax: +48 323733 819, e-mail: kamil_bujak@o2.pl

Received: 8.08.2018

Accepted: 11.10 .2018 
Table 1. Questions to be answered by the results of Silesian Registry of Out-of-Hospital Cardiac Arrest.

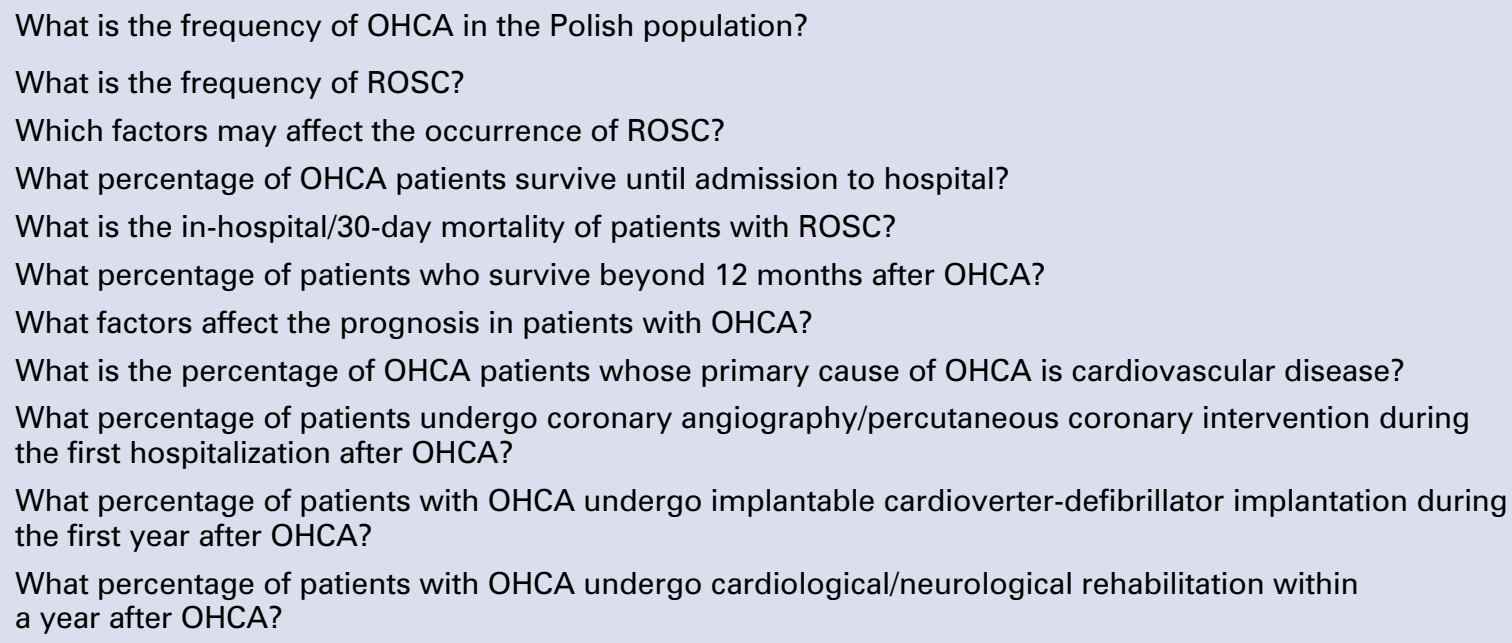

OHCA — out-of-hospital cardiac arrest; ROSC — return of spontaneous circulation

\section{Introduction}

Cardiovascular diseases are both the leading cause of death in adults of developed countries, and the most frequent cause of out-of-hospital cardiac arrest (OHCA) [1-5]. The introduction of the concept known as "chain of survival" has significantly increased the survival rate of patients with OHCA [4]. Nonetheless the mortality in this group of patients is still very high, and less than $10 \%$ of patients survive until hospital discharge [2]. Epidemiological data concerning OHCA in the European population is mainly provided from prospective registries, which number has increased over the last several years [3, 6-9]. Nonetheless, data on OHCA in Poland remains limited. The aim herein, therefore, was to create the Silesian Registry of Out-of-Hospital Cardiac Arrest (SIL-OHCA; ClinicalTrials.gov Identifier: NCT03654859) which covers a population of 2.7 million inhabitants of Upper Silesia. Main goals of SIL-OHCA are presented in Table 1. The study design of SIL-OHCA and the results of a 3-month pilot study are presented in this paper.

\section{Methods}

SIL-OHCA is prospective, population-based registry of $\mathrm{OHCA}$, a minimum duration was planned for 12 months, from January $1^{\text {st }}, 2018$ to December $31^{\text {st }}, 2018$ with the possibility of prolonging the study period. The first 3 months of the study ( $1^{\text {st }}$ January 2018 to $30^{\text {th }}$ March 2018) constituted the pilot phase. The area covered by the registry is a part of the Silesian Voivodeship $\left(3883 \mathrm{~km}^{2}, 1.2 \%\right.$ of the total area of Poland), this corresponds to the region of activity of the Voivodeship Rescue Service in Katowice. There are 2,700,000 inhabitants in the area covered by this registry ( $7 \%$ of the population of Poland) and the mean population density is 695 persons per $\mathrm{km}^{2}$. Voivodeship Rescue Service in Katowice is the biggest public, emergency medical services (EMS) provider in Poland and is the sole EMS provider in the area covered by SIL-OHCA registry, excluding Polish Medical Air Rescue. There are 88 EMS ambulances in the structures of Voivodeship Rescue Service in Katowice, including 66 ambulances, consisting of two paramedics, and 22 ambulances, consisting of two paramedics and a physician. On average the number of EMS responses of Voivodeship Rescue Service in Katowice is 250,000 per year. Voivodeship Rescue Service in Katowice follows cardiopulmonary resuscitation (CPR) algorithms based on European Resuscitation Council guidelines [10, 11].

From $1^{\text {st }}$ January to $30^{\text {th }}$ June 2018 (including the pilot phase of the study) all cases of OHCA with CPR started or continued by EMS and cases with confirmed OHCA and the return of spontaneous circulation (ROSC) before EMS arrival have been included in the study (regardless of the cause of OHCA and age of patients). Additionally, starting from $1^{\text {st }}$ July 2018 all OHCA cases where resuscitation was not attempted have been included as well.

All EMS of Voivodeship Rescue Service in Katowice are required to fill out a standardized, paper-based questionnaire, immediately after completing medical activities. The questionnaire template is presented in Figure 1. In the case of intervention of more than one EMS, data provided 
Silesian Registry of Out-of-Hospital Cardiac Arrest - Questionnaire template valid from 1st July 2018. Please fill out this questionnaire in every case of out-of-hospital cardiac arrest, regardless of whether CPR is attempted. Abbreviations: EMS - emergency medical service; CRT-P - implantable cardiac resynchronization therapy pacemaker; $C R T$-D - cardiac resynchronization therapy defibrillator; ICD - implantable cardioverter defibrillator; ROSC - return of spontaneous circulation.

\begin{tabular}{|l|l|l|l}
\hline A & $\begin{array}{l}\text { Date of birth (yyyy.mm.dd) } \square \square \square \square . \square \square . \square \square \\
\begin{array}{l}\text { Number of intervention: } \\
\square \square \square \square \square \square \square \square \square \square\end{array}\end{array}$ & Type of EMS: S $\square / \mathrm{P} \square$ & Age (only if date of birth is unknown) $\square \square \square$ years. \\
\hline & Sex $\square / \mathrm{F} \square$ & $\begin{array}{l}\text { Date/hour of receiving call } \\
\text { (yyyy.mm.dd)/(hh:mm): } \\
\square \square \square\end{array}$ \\
\hline
\end{tabular}

B EMS witnessed cardiac arrest?: Yes $\square$ / No $\square$ (if YES, pleas skip to part C)

Bystander witnessed cardiac arrest (collapse)? (other persons than EMS): Yes $\square$ / No $\square$

Did the dispatcher provide telephone CPR instructions to the caller? Yes $\square$ / No $\square$

\begin{tabular}{|l|l|}
\hline \multirow{2}{*}{ Did bystanders perform CPR before EMS arrival?: Yes $\square /$ No $\square$} & If YES what were they doing?: \\
& Compression only $\square /$ Compression + ventilations $\square$ \\
& $\begin{array}{l}\text { Did bystanders use AED?: } \\
\text { No } \square / \text { Yes, shock not delivered } \square / \text { Yes, } \\
\text { shock delivered } \square\end{array}$ \\
\hline
\end{tabular}

C Approximate time of cardiac arrest (yyyy.mm.dd)/(hh:mm) $\square \square \square \square . \square \square . \square \square / \square \square: \square \square$

Arrest location: home or residence $\square /$ workplace $\square /$ recreation event $\square /$ street/highway $\square$ / public building $\square /$ educational institution $\square /$ nursing home $\square$ / GP surgery $\square$ / other $\square$

Aetiology of cardiac arrest: medical (presumed cardiac, other medical, or unknown) $\square$ / traumatic $\square$ / drug overdose (medications, recreational drugs, ethanol or other) $\square /$ drowning $\square /$ electrocution $\square /$ asphyxial (external causes of asphyxia, such as foreign-body airway obstruction, hanging, or strangulation) $\square$

Source of information on medical history: family $\square$ / other witness $\square$ / medical records $\square$ / medical history unavailable $\square$

Comorbidities: previous myocardial infarction $\square$ / coronary artery disease (previous $P C I$ or $C A B G$ ) $\square$ / previous stroke $\square$ / diabetes $\square$ / malignancies $\square$ / other $\square$ (which?).

Implanted device: pacemaker or CRT-P $\square$ / ICD or CRT-D $\square$ / left ventricular assist device (heart pump) $\square$

Symptoms preceding cardiac arrest: none $\square$ / dyspnoea $\square$ / chest pain $\square$ / abdominal pain $\square$ / swelling $\square$ /

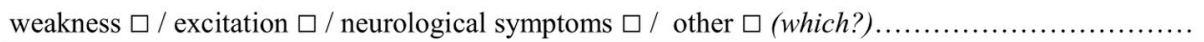

Duration of symptoms prior to cardiac arrest: unknown $\square$ / less than 10min $\square$ / less than 30min $\square$ / less than $1 \mathrm{~h}$ $\square / 1-24 \mathrm{~h} \square /$ over $24 \mathrm{~h} \square$

Was the patient unable to live independently prior cardiac arrest (required constant care; was unable to perform activities of daily living without the assistance of caregivers)? Yes $\square /$ No $\square$

PAGE $1 / 2$

Figure 1. Questionnaire template - A. Page 1/2. 


\begin{tabular}{|c|c|c|c|}
\hline \multirow[t]{9}{*}{ D } & \multicolumn{2}{|l|}{ CPR attempted by EMS?: Yes $\square /$ No $\square$} & $\begin{array}{l}\text { Reason for CPR withdrawal (if CPR attempted by EMS, } \\
\text { please skip this question): obviously dead } \square \text { / DNAR } \square \text { / } \\
\text { wish family } \square \text { / EMS decision } \square \text { / ROSC before EMS arrival } \\
\square \text { / successful ICD-shock } \square\end{array}$ \\
\hline & \multicolumn{3}{|c|}{ (if CPR NOT attempted by EMS, please skip to part F) } \\
\hline & \multicolumn{3}{|c|}{$\begin{array}{l}\text { First monitored rhythm after cardiac arrest: VF } \square \text { / pulseless VT } \square \text { / PEA } \square \text { / asystole } \square \text { / bradycardia } \square \text { / AED } \\
\text { shockable (if bystanders used AED before EMS arrival) } \square \text { / AED nonshockable (if bystanders used AED before } \\
\text { EMS arrival) }\end{array}$} \\
\hline & Defibrillation: Yes $\square /$ No $\square$ & \multicolumn{2}{|c|}{$\begin{array}{l}\text { If YES: } \\
\text { Number of shocks } \square \square \\
\text { Time of the first shock (hh:mm) } \square \square: \square \square\end{array}$} \\
\hline & \multicolumn{3}{|c|}{$\begin{array}{l}\text { Airway control during CPR: oropharyngeal tube } \square \text { / nasopharyngeal tube } \square \text { / laryngeal mask/tube } \square / \\
\text { endotracheal tube } \square \text { / surgical airway } \square / \text { none used } \square / \text { other } \square \text { (which?) } \ldots \ldots \ldots \ldots \ldots \ldots \ldots \ldots \ldots \ldots \ldots \ldots \ldots \ldots \ldots \ldots \ldots \ldots \ldots \ldots\end{array}$} \\
\hline & \multicolumn{3}{|c|}{ Ventilation during CPR: bag valve mask $\square /$ respirator $\square$} \\
\hline & \multicolumn{3}{|c|}{ 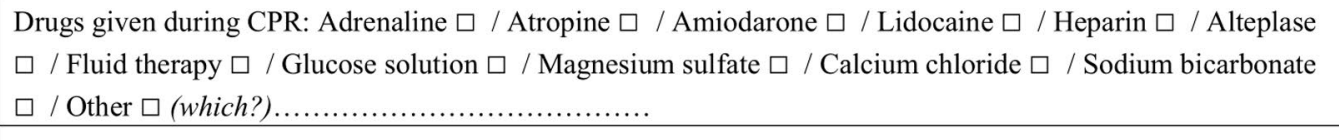 } \\
\hline & \multicolumn{3}{|c|}{ Vascular access: IV $\square /$ IO $\square /$ endotracheal $\square$} \\
\hline & \multicolumn{3}{|l|}{ Mechanical CPR: Yes $\square /$ No $\square$} \\
\hline \multirow[t]{6}{*}{$\mathbf{E}$} & \multicolumn{3}{|c|}{$\begin{array}{l}\text { Did the patient achieve ROSC at any point during CPR? Yes } \square / \text { No } \square \\
\text { (if NO, please skip to part F) }\end{array}$} \\
\hline & \multicolumn{3}{|c|}{ Results of measurements after ROSC: BP $\square \square \square / \square \square \square \mathrm{mmHg}$; glycemia $\square \square \square \mathrm{mg} / \mathrm{dl}$; } \\
\hline & \multicolumn{3}{|l|}{ GCS after ROSC: $\square \square$ points } \\
\hline & \multicolumn{3}{|c|}{$\begin{array}{l}\text { Procedures after ROSC: 12-Lead ECG } \square \text {; ECG transmission } \square \text {; cardioversion } \square \text {; transthoracic pacing } \square \text {; } \\
\text { targeted temperature management } \square\end{array}$} \\
\hline & \multicolumn{3}{|l|}{ ECG description... } \\
\hline & \multicolumn{3}{|c|}{ Presence of STEMI (in 12-Lead ECG performed after ROSC): Yes $\square$ / No $\square$} \\
\hline \multirow[t]{4}{*}{$\mathbf{F}$} & \multicolumn{3}{|l|}{ Patient's status (check the appropriate box): } \\
\hline & \multicolumn{2}{|c|}{$\begin{array}{l}\text { Transfer to the hospital with sustained ROSC } \square \rightarrow \\
\text { or }\end{array}$} & \multirow[t]{2}{*}{$\begin{array}{l}\text { Time of hospital admission (hh:mm): } \square \square: \square \square \\
\text { Hospital name: } \\
\text { Address of the hospital: }\end{array}$} \\
\hline & \multicolumn{2}{|c|}{$\begin{array}{l}\text { Transfer to the hospital with ongoing CPR } \square \rightarrow \\
\text { or }\end{array}$} & \\
\hline & Withholding CPR $\square \rightarrow$ & & $\begin{array}{l}\text { Time of the decision to withhold CPR (hh:mm): } \\
\square \square: \square \square\end{array}$ \\
\hline
\end{tabular}

Thank you for completing our survey!

PAGE $2 / 2$

Figure 1. cont. Questionnaire template - B. Page 2/2. 


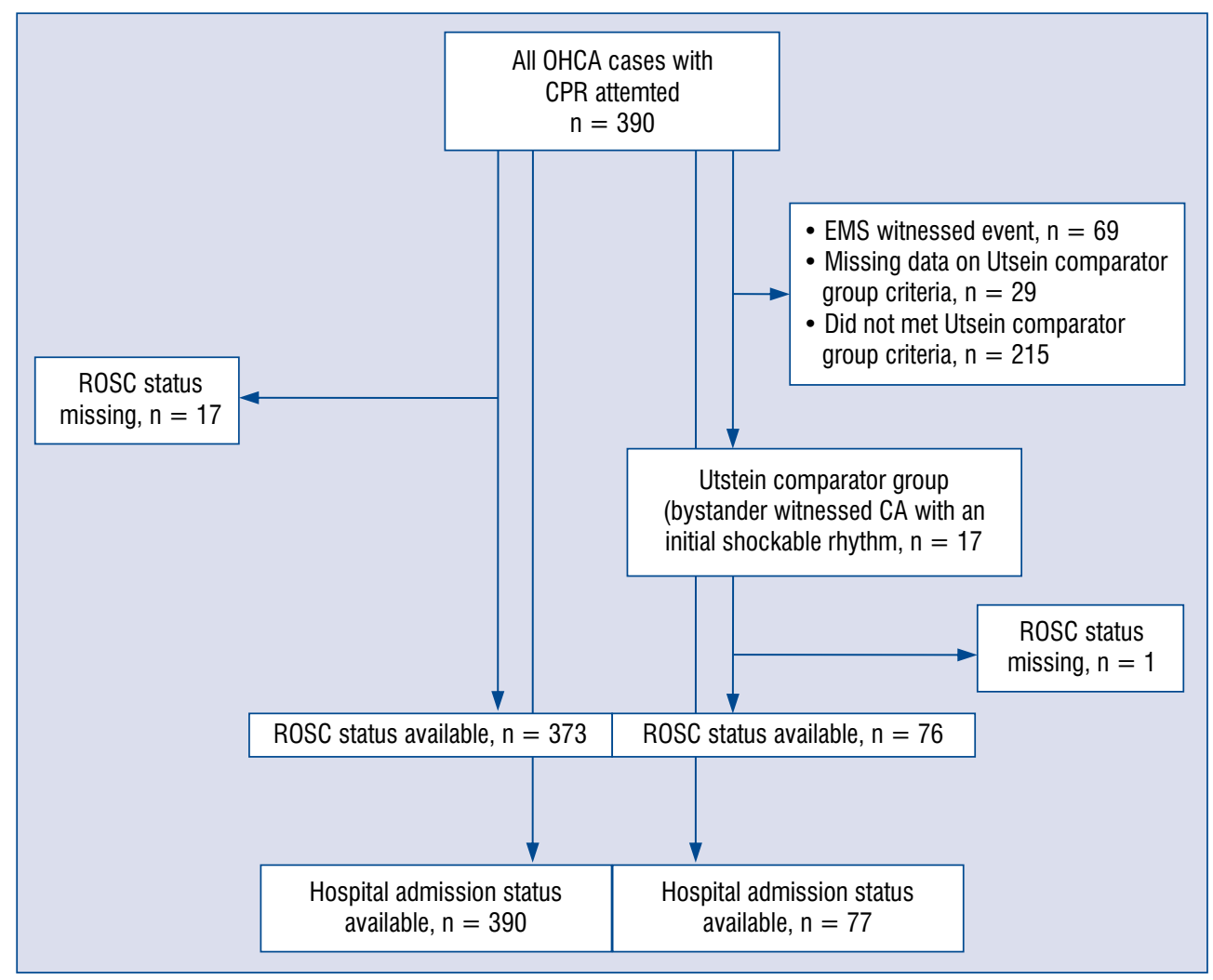

Figure 2. Flow-chart of the pilot study population; CA — cardiac arrest; CPR — cardiopulmonary resuscitation; EMS — emergency medical services; OHCA — out-of-hospital cardiac arrest; ROSC — return of spontaneous circulation.

by the EMS, that transferred the patient to the hospital or decided to stop CPR are taken into consideration. Subsequently, all questionnaires are transferred to the headquarters of Voivodeship Rescue Service, where they are archived digitally.

The questionnaire template, as well as all terms and definitions used in SIL-OHCA are based on the updated Utstein guidelines on reporting OHCA (2015) [1].

\section{Follow-up}

All patients transferred to the hospital by EMS are followed-up for a minimum of 1 year from the OHCA occurrence for all-cause mortality during initial hospitalization, within 30 days and at 12 months. The follow-up data will be sourced from the SILesian CARDiovascular (SILCARD) database, which is a joint initiative of the Silesian Center for Heart Diseases and the National Health Fund. SILCARD is a registry of administrative data, which comprises inter alia patients hospitalized due to OHCA within the Silesian Voivodeship area. Detailed information on the SILCARD registry have been published previously [12]. Data from the SILCARD registry enables to determine the etiology of OHCA (based on the final diagnosis during the first hospitalization after OHCA) to assess the percentage of patients who underwent procedures such as myocardial revascularization or cardioverter-defibrillator implantation, and to estimate the percentage of patients undergoing cardiac and neurological rehabilitation. Prehospital and follow-up data will be linked based on a patient's date of birth, individual code of the unit (hospital, department) to which the patient was transferred and the date of admission to the unit. An estimated percentage of patients who survived beyond admission to hospital, and for whom follow-up was available in more than $99 \%$ of patients with available date of birth and admission status. The percentage of patients with accessible date of birth in the pilot study was $96.1 \%$ and admission status was available for all patients. In cases where data linking baseline characteristics with follow-up are ambiguous i.e. more than 1 patient born on the same day is admitted to a given unit on a given day then patient follow-up data will not be taken into consideration. Based on currently available SILCARD data, it was estimated that the percentage of these patients would not exceed $1 \%$.

The study conformed to the Declaration of Helsinki. Approval for research was waived by the 
Bioethics Committee of the Silesian Medical Chamber, given the observational nature of the study.

\section{Statistical analysis}

Dichotomous variables are presented as number of cases (percentage). Continuous variables are presented as median and (interquartile range [IQR]). Analysis of the pilot-study data was performed both for the whole cohort of EMS-treated patients, as well as the subgroup of patients with bystander witnessed cardiac arrest and an initial shockable rhythm (Utstein comparator group [1]). There were no prespecified analyses in the SIL-OHCA registry.

\section{Results}

\section{Results of 3-month pilot study}

During the 3-month pilot phase of the study there were 390 cases of OHCA (128 women, 262 men), which is $0.6 \%$ of EMS responses during the period analyzed. A flow-chart of the pilot study population is presented in Figure 2. The median age of patients was 66 years (range 0-97 years; IQR 56-77 years). It was estimated that there are about 1560 cases of OHCA in the area covered per year, which corresponds with the 57 cases per 100,000 population per year. Baseline characteristics of the study population is shown in Table 2. The most frequent etiology of OHCA was medical. Asystole was the most common initial rhythm. Shockable rhythm was present in $25.8 \%$ of patients. The most frequent location of $\mathrm{OHCA}$ was home/residence, and $89.9 \%$ of events were witnessed. CPR was performed by bystander witnesses in $47.9 \%$ of OHCA cases. Automated external defibrillator (AED) was used by witnesses in $3(0.8 \%)$ patients. ROSC occurred in $35.1 \%$ of the whole cohort, and in $51.3 \%$ of patients who met the Utstein comparator group criteria (bystander witnessed cardiac arrest with an initial shockable rhythm). In the whole study group, $28.7 \%$ of patients were admitted to hospital, including $2.8 \%$ of patients who were admitted during ongoing CPR. In the Utstein comparator group, $41.6 \%$ of patients were admitted to hospital, including $1.5 \%$ of patients during ongoing CPR.

\section{Discussion}

Large-scale medical registries are the primary source of information on the epidemiology of OHCA $[2,13,14]$. They enable analyzing trends in the occurrence, treatment approaches and prognosis in OHCA $[15,16]$. International EuReCa One study encompassing 10,682 OHCA cases in 27 European countries have indicated substantial differences in the frequency of OHCA and survival to hospital discharge among participating countries [2]. In this registry 275 patients with OHCA from Poland were included, and inhabited only small cities ( $<100,000$ inhabitants) or villages [2]. The biggest prospective registry of OHCA in the Polish population was described by Cebula et al. [8], who provided a lot of valuable information on epidemiology of OHCA, however it did not include long-term follow-up. Aforementioned limitations of the previous studies provided reasons to introduce SIL-OHCA covering a population of 2.7 million inhabitants, residing in the highly urbanized region of Upper Silesia.

To the best of our knowledge, there have been published results in one prospective and three retrospective registries encompassing the Polish population to date $[8,17-19]$, as well as data from Poland which was reported in the international EuReCa ONE study [2]. The frequency of OHCA with attempted CPR was 70-128 cases per 100,000 population per year in these registries. The incidence of OHCA in the Upper Silesian population was estimated on the basis of the present 3 -month pilot study when there were 57 cases per 100,000 inhabitants per year, which was close to the mean frequency in the European population (49 cases/100,000 inhabitants per year) [2]. Approximately two-thirds of patients with OHCA included in the examined registry were male, this finding was similar to other studies [8, 18]. ROSC in the present population was achieved in $35.1 \%$ of patients, which confirms previously published data from Poland, where ROSC occurred in 30.5-31.2\% of cases $[8,18]$. In addition, in a homogeneous sub-population meeting Utstein comparator group criteria, the ROSC frequency was $51.3 \%$, which corresponds to data from European registries and is slightly lower than that reported on average in Europe (56.8\%) [2]. Finally, of all patients with OHCA included in the pilot study, 25.9\% survived the event (were transferred to the hospital with sustained ROSC). This finding is also very similar to the results of EuReCa ONE, where the event survival rate was $25.2 \%$ [2].

The results of the present 3-month pilot study have indicated an inadequate participation of bystanders in CPR before the arrival of EMS, which has a significant impact on the percentage of cases with shockable rhythm, and long-term outcome [20-22]. Hasselqvist-Ax et al. [20] reported, based on data from nationwide Swedish registry of OHCA, 
Table 2. Demographic data, baseline characteristics and outcome of patients with OHCA included in Silesian Registry of Out-of-Hospital Cardiac Arrest.

\begin{tabular}{|c|c|c|}
\hline Variable & $\begin{array}{l}\text { Whole population } \\
\qquad(\mathrm{n}=390)\end{array}$ & $\begin{array}{l}\text { Percentage of cases } \\
\text { with missing data }\end{array}$ \\
\hline Age [years] & 66 [56-77] & 3.8 \\
\hline Sex: & & 0 \\
\hline Male & $262(67.2)$ & \\
\hline Female & $128(32.8)$ & \\
\hline OHCA etiology: & & 1.5 \\
\hline Medical & $299(77.9)$ & \\
\hline Asphyxial & $44(11.5)$ & \\
\hline Traumatic & $9(2.3)$ & \\
\hline Other & $32(8.3)$ & \\
\hline Location of OHCA: & & 0.2 \\
\hline Home/residence & $282(72.5)$ & \\
\hline Public space & $64(16.5)$ & \\
\hline Other & $43(11.1)$ & \\
\hline Response time [min] & $8[6-11]$ & 1.3 \\
\hline EMS witnessed OHCA & 69 (17.9) & 0 \\
\hline Bystander CPR & $186(47.9)$ & 0.5 \\
\hline Comorbidities: & & 0 \\
\hline Previous MI & $51(13.1)$ & \\
\hline Previous stroke & $37(9.5)$ & \\
\hline Malignancies & $27(6.9)$ & \\
\hline Previously implanted cardioverter-defibrillator & $4(1.0)$ & 0 \\
\hline First monitored rhythm: & & 4.6 \\
\hline VF/pulseless VT & $96(25.8)$ & \\
\hline Asystole/PEA & $276(74.2)$ & \\
\hline 12-lead ECG performed after ROSC & $54(41.2)$ & 0 \\
\hline Presence of STEMI & $16(29.6)$ & 58.8 \\
\hline $\begin{array}{l}\text { Patients who met the Utstein comparator group criteria } \\
\text { (bystander witnessed CA with an initial shockable rhythm) }\end{array}$ & $77(19.7)$ & 7.4 \\
\hline ROSC (whole population) & $131(35.1)$ & 4.4 \\
\hline Status of patients on hospital admission (whole population): & & 0 \\
\hline Died before hospital admission & $278(71.3)$ & \\
\hline Admission to hospital with ROSC & $101(25.9)$ & \\
\hline Admission to hospital during ongoing CPR & $11(2.8)$ & \\
\hline ROSC (Utstein comparator group) & $39(51.3)$ & 1.3 \\
\hline $\begin{array}{l}\text { Status of patients on hospital admission } \\
\text { (Utstein comparator group): }\end{array}$ & & 0 \\
\hline Died before hospital admission & $45(58.4)$ & \\
\hline Admission to hospital with ROSC & $31(40.3)$ & \\
\hline Admission to hospital during ongoing CPR & $1(1.3)$ & \\
\hline
\end{tabular}

Dichotomous variables are presented as number of cases (percentage). Continous variables are presented as median (intequartile range); CA — cardiac arrest; CPR - cardiopulmonary resuscitation; ECG - electrocardiography; OHCA - out-of-hospital cardiac arrest; MI myocardial infarction; PEA - pulseless electrical activity; ROSC - return of spontaneous circulation; STEMI - ST-elevation myocardial infarction; VF — ventricular fibrillation; VT — ventricular tachycardia 
that CPR performed by bystanders was associated with 30-day survival, which is more than twice as high as that associated with no CPR before EMS arrival. A high percentage of cases with CPR performed before EMS arrival in Sweden is probably due to the fact that almost one third of the Swedish population have undergone CPR training during the past three decades [20,23]. In this context Sweden is a role model for other nations [23]. In addition, Nakahara et al. [21] reported that in Japan, between 2005 and 2012, increase in neurologically intact survival in patients with OHCA was observed, which was associated with an increased rate of bystander CPR. Another critical element of the "chain of survival", besides CPR, is rapid defibrillation [24]. Hansen et al. [25] showed that over $30 \%$ of patients with OHCA, who were defibrillated by bystanders, survived to hospital discharge. The AED was used by bystanders in less than $1 \%$ of cases included in SIL-OHCA, which may have been be due to the low availability of AED, as well as insufficient knowledge of society about the possibility of using the device. The use of AED by bystanders in the present population was over five times lower than reported in the United States, according to study by van Diepen et al. [26]. Aforementioned factors affect an unsatisfactory percentage of ROSC, as well as the percentage of patients admitted to the hospital with sustained ROSC, which, despite being close to the outcomes reported on average in the European population, is lower than results achieved in some Western European countries $[2,27,28]$. There is a critical need for interventions to increase the frequency of bystander CPR and AED use in the Polish population to improve survival rate in patients with OHCA.

The SIL-OHCA registry, which is an initiative of the Voivodeship Rescue Service in Katowice in cooperation with the Silesian Center for Heart Diseases in Zabrze, is, to the best of our knowledge, the first prospective OHCA registry which aims to assess long-term prognosis for this group of patients in Poland. Results of the 3-month pilot study confirmed the possibility of creating registry which covers all patients with OHCA in the region of activity of Voivodeship Rescue Service in Katowice. In the pilot phase of the study, the percentage of missing data was low, and results presented were comparable to previous studies. We believe that the SIL-OHCA registry will provide reliable epidemiological data on OHCA, including the prehospital data and long-term follow-up. Owing to the data collected, it will be possible to identify factors that need improvement in order to increase both the short- and long-term survival rates of patients with OHCA.

\section{Conclusions}

Short-term results of OHCA patients in Poland are still unsatisfactory. It is believed that owing to the prospective registry, medical practitioners will be able to identify factors that require modification in order to improve short- and long-term prognosis in patients with OHCA.

\section{Conflict of interest: None declared}

\section{References}

1. Perkins G, Jacobs I, Nadkarni V, et al. Cardiac Arrest and Cardiopulmonary Resuscitation Outcome Reports: Update of the Utstein Resuscitation Registry Templates for Out-of-Hospital Cardiac Arrest. Resuscitation. 2015; 96: 328-340, doi: 10.1016/j. resuscitation.2014.11.002.

2. Gräsner JT, Lefering R, Koster RW, et al. EuReCa ONE-27 Nations, ONE Europe, ONE Registry: A prospective one month analysis of out-of-hospital cardiac arrest outcomes in 27 countries in Europe. Resuscitation. 2016; 105: 188-195, doi: 10.1016/j.resuscitation.2016.06.004, indexed in Pubmed:27321577.

3. Masterson S, Wright P, O'Donnell C, et al. Urban and rural differences in out-of-hospital cardiac arrest in Ireland. Resuscitation. 2015; 91: 42-47, doi:10.1016/j.resuscitation.2015.03.012, indexed in Pubmed: 25818707.

4. Iwami T, Nichol G, Hiraide A, et al. Continuous improvements in "chain of survival" increased survival after out-of-hospital cardiac arrests: a large-scale population-based study. Circulation. 2009; 119(5): 728-734, doi: 10.1161/CIRCULATIONAHA.108.802058, indexed in Pubmed: 19171854.

5. Freund B, Kaplan PW. A review of the utility of a hypothermia protocol in cardiac arrests due to non-shockable rhythms. Cardiol J. 2017; 24(3): 324-333, doi: 10.5603/CJ.a2017.0016, indexed in Pubmed: 28150290.

6. Hubert H, Tazarourte K, Wiel E, et al. Rationale, methodology, implementation, and first results of the French out-ofhospital cardiac arrest registry. Prehosp Emerg Care. 2014; 18(4): 511-519, doi: 10.3109/10903127.2014.916024, indexed in Pubmed: 24877567.

7. Strömsöe A, Svensson L, Axelsson ÅB, et al. Improved outcome in Sweden after out-of-hospital cardiac arrest and possible association with improvements in every link in the chain of survival. Eur Heart J. 2015; 36(14): 863-871, doi: 10.1093/eurheartj/ ehu240, indexed in Pubmed: 25205528.

8. Cebula GM, Osadnik S, Wysocki M, et al. Comparison of the early effects of out-of-hospital resuscitation in selected urban and rural areas in Poland. A preliminary report from the Polish Cardiac Arrest Registry by the Polish Resuscitation Council. Kardiol Pol. 2016; 74(4): 356-361, doi:10.5603/KP.a2016.0001, indexed in Pubmed: 26779850.

9. Ristagno G, Semeraro F, Radeschi G, et al. The "Italian Registry of Cardiac Arrest - RIAC", a National achievement to portrait the Italian reality and to contribute to the wider European vision by "EuReCa". Resuscitation. 2014; 85(12): e193-e194, 
doi: 10.1016/j.resuscitation.2014.09.015, indexed in Pubmed: 25265522.

10. Perkins GD, Olasveengen TM, Maconochie I, et al. European Resuscitation Council. European Resuscitation Council Guidelines for Resuscitation: 2017 update. Resuscitation. 2018; 123: 43-50, doi: 10.1016/j.resuscitation.2017.12.007, indexed in Pubmed: 29233740.

11. Monsieurs KG, Nolan JP, Bossaert LL, et al. ERC Guidelines 2015 Writing Group. European Resuscitation Council Guidelines for Resuscitation 2015: Section 1. Executive summary. Resuscitation. 2015; 95: 1-80, doi: 10.1016/j.resuscitation.2015.07.038, indexed in Pubmed: 26477410.

12. Gąsior M, Pres D, Wojakowski W, et al. Causes of hospitalization and prognosis in patients with cardiovascular diseases. Secular trends in the years 2006-2014 according to the SILesian CARDiovascular (SILCARD) database. Pol Arch Med Wewn. 2016; 126(10): 754-762, doi: 10.20452/pamw.3557, indexed in Pubmed: 27650214.

13. van Diepen S, Abella BS, Bobrow BJ, et al. Multistate implementation of guideline-based cardiac resuscitation systems of care: description of the HeartRescue project. Am Heart J. 2013; 166(4): 647-653.e2, doi: 10.1016/.j.ahj.2013.05.022, indexed in Pubmed: 24093843.

14. Berger S. Survival from out-of-hospital cardiac arrest: are we beginning to see progress? J Am Heart Assoc. 2017; 6(9), doi:10.1161/JAHA.117.007469, indexed in Pubmed: 28939721.

15. Okubo M, Kiyohara K, Iwami T, et al. Nationwide and regional trends in survival from out-of-hospital cardiac arrest in Japan: a 10-year cohort study from 2005 to 2014. Resuscitation. 2017; 115: 120-128, doi: 10.1016/j.resuscitation.2017.03.036, indexed in Pubmed: 28392371.

16. Ro YS, Shin SDo, Kitamura T, et al. Temporal trends in out-ofhospital cardiac arrest survival outcomes between two metropolitan communities: Seoul-Osaka resuscitation study. BMJ Open. 2015; 5(6): e007626, doi: 10.1136/bmjopen-2015-007626, indexed in Pubmed: 26059524.

17. Kłosiewicz T, Skitek-Adamczak I, Zieliński M. Emergency medical system response time does not affect incidence of return of spontaneous circulation after prehospital resuscitation in one million central European agglomeration residents. Kardiol Pol. 2017; 75(3): 240-246, doi:10.5603/KP.a2016.0181, indexed in Pubmed: 27995600.

18. Gach D, Nowak JU, Krzych ŁJ. Epidemiology of out-of-hospital cardiac arrest in the Bielsko-Biala district: a 12-month analysis. Kardiol Pol. 2016; 74(10): 1180-1187, doi: 10.5603/ KP.a2016.0086, indexed in Pubmed: 27221961.

19. Szczerbinski S, Ratajczak J, Lach P, et al. Epidemiology and chronobiology of out-of-hospital cardiac arrest in a subpopu- lation of southern Poland: A two-year observation. Cardiol J. 2020; 27(1): 16-24, doi: 10.5603/CJ.a2018.0025, indexed in Pubmed: 29611174.

20. Hasselqvist-Ax I, Riva G, Herlitz J, et al. Early cardiopulmonary resuscitation in out-of-hospital cardiac arrest. N Engl J Med. 2015; 372(24): 2307-2315, doi: 10.1056/NEJMoa1405796, indexed in Pubmed: 26061835.

21. Nakahara S, Tomio J, Ichikawa M, et al. Association of Bystander Interventions With Neurologically Intact Survival Among Patients With Bystander-Witnessed Out-of-Hospital Cardiac Arrest in Japan. JAMA. 2015; 314(3): 247-254, doi: 10.1001/ jama.2015.8068, indexed in Pubmed: 26197185.

22. Jorge-Soto C, Abilleira-González M, Otero-Agra M, et al. Schoolteachers as candidates to be basic life support trainers: A simulation trial. Cardiol J. 2018 [Epub ahead of print], doi: 10.5603/ CJ.a2018.0073, indexed in Pubmed: 30009374.

23. Strömsöe A, Andersson B, Ekström L, et al. Education in cardiopulmonary resuscitation in Sweden and its clinical consequences. Resuscitation. 2010; 81(2): 211-216, doi: 10.1016/j. resuscitation.2009.10.014, indexed in Pubmed: 19926389.

24. Krammel M, Schnaubelt S, Weidenauer D, et al. Gender and age-specific aspects of awareness and knowledge in basic life support. PLoS One. 2018; 13(6): e0198918, doi: 10.1371/journal. pone.0198918, indexed in Pubmed: 29894491.

25. Hansen CM, Kragholm K, Granger CB, et al. The role of bystanders, first responders, and emergency medical service providers in timely defibrillation and related outcomes after out-of-hospital cardiac arrest: Results from a statewide registry. Resuscitation. 2015; 96: 303-309, doi:10.1016/j.resuscitation.2015.09.002, indexed in Pubmed: 26386371.

26. van Diepen S, Girotra S, Abella BS, et al. Multistate 5-Year Initiative to Improve Care for Out-of-Hospital Cardiac Arrest: Primary Results From the HeartRescue Project. J Am Heart Assoc. 2017; 6(9), doi: 10.1161/JAHA.117.005716, indexed in Pubmed: 28939711.

27. Gräsner JT, Meybohm P, Fischer M, et al. A national resuscitation registry of out-of-hospital cardiac arrest in Germany-a pilot study. Resuscitation. 2009; 80(2): 199-203, doi: 10.1016/j.resuscitation.2008.10.008, indexed in Pubmed: 19081171.

28. Blom MT, Beesems SG, Homma PCM, et al. Improved survival after out-of-hospital cardiac arrest and use of automated external defibrillators. Circulation. 2014; 130(21): 1868-1875, doi: 10.1161/CIRCULATIONAHA.114.010905, indexed in Pubmed: 25399395. 